This item was submitted to Loughborough's Research Repository by the author.

Items in Figshare are protected by copyright, with all rights reserved, unless otherwise indicated.

\title{
Element interactivity as a factor influencing the effectiveness of worked example-problem solving and problem solving-worked example sequences
}

\section{PLEASE CITE THE PUBLISHED VERSION}

https://doi.org/10.1111/bjep.12317

\section{PUBLISHER}

Wiley

\section{VERSION}

AM (Accepted Manuscript)

\section{PUBLISHER STATEMENT}

This is the peer reviewed version of the following article: Chen, Ouhao; Retnowati, Endah; Kalyuga, Slava (2020): Element interactivity as a factor influencing the effectiveness of worked example-problem solving and problem solving-worked example sequences. British Journal of Educational Psychology, 90 (S1), pp.210-223, which has been published in final form at https://doi.org/10.1111/bjep.12317]. This article may be used for noncommercial purposes in accordance with Wiley Terms and Conditions for Use of Self-Archived Versions

\section{LICENCE}

CC BY-NC-ND 4.0

\section{REPOSITORY RECORD}

Chen, Ouhao, Endah Retnowati, and Slava Kalyuga. 2019. "Element Interactivity as a Factor Influencing the Effectiveness of Worked Example-problem Solving and Problem Solving-worked Example Sequences". Loughborough University. https://hdl.handle.net/2134/12052710.v1. 


\title{
Element Interactivity as a Factor Influencing the Effectiveness of Worked Example- Problem Solving and Problem Solving-Worked Example Sequences
}

\begin{abstract}
Background

The worked example effect in cognitive load theory suggests that providing worked examples first followed by solving similar problems would facilitate students' learning. Using problem solving-worked example sequence is another way of implementing example-based instruction. Although research has demonstrated the superiority of worked example-problem solving sequence on learning materials that presumably are high in element interactivity for novices, none of the previous studies have compared the two sequences with levels of element interactivity experimentally manipulated in a strictly controlled manner.
\end{abstract}

Aims

The reported study aimed to investigate the effects of levels of element interactivity of the learning tasks and levels of learner prior knowledge on the effectiveness of two alternative example-based sequences, worked example-problem solving vs. problem solving-worked example.

Samples

52 Year 5 students, around 10 to 11 years old, from a primary school in Indonesia participated in Experiment 1, and 96 Year 8 students, around 13 to 14 years old, from a secondary school in Indonesia participated in Experiment 2.

Method

2 (sequences: worked example-problem solving vs. problem solving-worked example) $\times 2$ (levels of element interactivity: low vs. high) experimental design, with the second factor repeatedly measured, was used in the two experiments conducted with learners at different levels of prior knowledge.

Results

The results showed the advantage of using worked example-problem solving sequence for learning materials high in element interactivity, especially for novice learners, whereas there were no differences between the worked example-problem solving and problem solving-worked example sequences for learning materials low in element interactivity for more knowledgeable learners.

Conclusions

This study not only replicated the results of previous studies, but also extended their findings by experimentally manipulating levels of element interactivity of learning materials. 
Worked Example-Problem Solving and Problem Solving-Worked Example

Keywords: Cognitive Load Theory, worked examples, problem solving, element interactivity, expertise 


\section{Introduction}

Providing full-guidance instruction, such as a worked example, followed by solving a similar problem (worked example-problem solving sequence) has been widely demonstrated to be an effective and efficient approach within the framework of cognitive load theory (worked example effect; see Sweller, Ayres, and Kalyuga, 2011, for a comprehensive overview). Also, there are a few studies that have investigated the reversed sequence, problem solving-worked example, as another form of example-based learning (e.g., Reisslein, Atkinson, Seeling, \& Reisslein, 2006; Van Gog, Kester \& Paas, 2011; Hsu, Kalyuga \& Sweller, 2015). The two experiments reported in this paper conceptually replicated the studies of Van Gog et al. (2011) and Reisslein et al. (2006) by comparing the alternative example-problem and problem-example sequences, with added novelty of controlling levels of element interactivity of learning materials and levels of learner expertise. The paper describes the experiments and their results, and concludes with educational implications of the reported findings.

\section{Cognitive load theory}

Cognitive load theory is an instructional theory that is based on our knowledge of human cognitive architecture. The most important aspect of this architecture is the relations between working memory and long-term memory (Sweller \& Sweller, 2006). Because of its very limited capacity (Cowan, 2001; Miller, 1956) and limited duration (Peterson \& Peterson, 1959), working memory cannot process or hold more than a few novel elements of information at one time. However, long-term memory has unlimited capacity and duration in holding organized knowledge structures (schemas). When the relevant schemas in long-term memory are activated and transferred to working memory, the effective working memory capacity can be substantially increased by encapsulating many elements of information into a small number of chunks based 
on those schemas (Ericsson \& Kintsch, 1995). Cognitive load theory aims to generate innovative instructional methods to reduce learner working memory load.

\section{Worked example effect and worked example-problem solving sequence}

Working example-problem solving sequence is suggested within the framework of cognitive load theory as a form of example-based learning. The original studies of worked example effect demonstrated that providing a worked example followed by solving a similar problem would facilitate students' learning, compared to solving two problems continuously (Cooper \& Sweller, 1987; Sweller \& Cooper, 1985). Due to the above characteristics of human cognitive architecture, novice learners could more effectively acquire information structures from studying worked examples than from generating solution themselves during problem solving which would involve heavy working memory load. Also, worked example-problem solving sequence is assumed to be more motivating for students as they would know that a similar problem would follow the worked example (Sweller \& Cooper, 1985).

The advantages of using worked examples and example-problem sequence have been well-documented in many studies across different domains, starting from the very first study with algebra tasks. Sweller and Cooper (1985) conducted five experiments in solving algebra manipulation problems using Year 9, Year 11 and university mathematics students. The results from Experiments 2 to 5 indicated that using worked examples not only facilitated students' learning but also reduced processing time and mathematics errors. Similarly, in the domain of basic statistics (such as concepts of median and mode), Paas (1992) compared conventional problem, worked example and completion of partial worked example conditions. The results suggested that the completion of partial worked example and worked example conditions were both superior to conventional problem solving condition with less time and effort. The similar 
Worked Example-Problem Solving and Problem Solving-Worked Example

findings were also demonstrated in the areas of physics (Van Gog et al., 2011) and geometry (Paas \& Merriënboer, 1994; Schwonke, Renkl, Krieg, Wittwer, Aleven, \& Salden, 2009). Kirschner, Sweller and Clark (2006) also strongly argued for the effectiveness of using worked examples rather than problem-based approaches in teaching, especially for novice learners.

However, the effectiveness of using worked example-problem solving sequence may be moderated by the levels of element interactivity. The next section will discuss this issue in details.

\section{Element interactivity}

Element interactivity is the core concept in cognitive load theory. Interactive elements are the interconnected elements of information that must be processed simultaneously in working memory in order to achieve understanding (Sweller et al., 2011).

Levels of element interactivity. The levels of element interactivity are determined by estimating the number of interconnected elements that need to be processed at the same time to achieve understanding (Sweller \& Chandler, 1994; Tindall-Ford, Chandler, \& Sweller, 1997). When students are required to memorize chemical symbols, such as $F e$ for iron, they could memorize it without referring to other symbols, for example $C u$ for cooper. They could memorize each symbol individually. Similarly, when learning English vocabulary, Dog could be memorized separately from Cat. This type of learning materials is low in element interactivity as elements are not interconnected and could be processed individually. In contrast, when solving the equation $3 x+5=8$ for $x$, the elements of this equation could not be processed individually, otherwise we could not understand the question. Therefore, the elements $(3, x,+, 5,=, 8)$ are 
interconnected and must be processed simultaneously in working memory to understand and solve this equation successfully.

Element interactivity and the role of expertise. The levels of element interactivity are also affected by levels of learner expertise or prior domain-specific knowledge (Chen, Kalyuga, \& Sweller, 2017; Chen, Retnowati \& Kalyuga, 2018). For a given task, learners with low expertise in the task's domain may encounter more interactive elements, rendering the task being high in element interactivity, whereas, at the same time, more knowledgeable learners could chunk elements to reduce the number of interactive elements, thus lowering the level of element interactivity. Therefore, for experts, the same task would become low in element interactivity. With the increase in learners' expertise, followed by the decrease in the level of element interactivity, the instructional procedures that are effective for novices may become ineffective for experts, indicating an expertise reversal effect (Kalyuga, 2007).

Element interactivity and worked example-problem solving sequence. Chen, Kalyuga and Sweller $(2015,2016 a, 2016 b)$ found that element interactivity might moderate the effectiveness of worked example-problem solving sequences in the domain of mathematics. In their experiments, two instructional effects, the worked example and generation effects, were tested. When testing for the generation effect, a list of simple geometry formulas (low in element interactivity) was used: students either generated or read formulas. The results showed preference for the generation group in memorizing the list of formulas.

When testing for the worked example effect, students were required to apply some of the geometry formulas in the list to calculate the area of compound shapes (high element interactivity tasks). Some of the participants were presented with a worked example followed by a similar problem to solve, while others were required to solve the equivalent number of 
problems without any worked examples. The results showed advantages of the worked exampleproblem solving sequence, indicating a worked example effect. Therefore, for materials low in element interactivity, generation was superior to worked examples, whereas for materials high in element interactivity, the result was reversed.

Since levels of learner expertise affect the levels of element interactivity, when testing the same sets of materials with more knowledgeable learners, all materials became low in element interactivity. Accordingly, the results indicated the generation effect for all sets of materials with expertise reversal effects found across multiple experiments. It is very likely that a similar kind of interaction exists between the effectiveness of worked example-problem solving, problem solving-worked example sequences and levels of element interactivity (which are affected by levels of learner expertise).

\section{Studies of problem solving-worked example sequence}

Most of studies within the framework of cognitive load theory have investigated and established the effectiveness of worked example-problem solving sequences. However, examplebased learning may also be implemented in the form of a problem solving-worked example sequence. The rationale for using the problem solving-worked example design is that learners may face challenges and knowledge deficiencies when solving problems, which may motivate them to focus better on the following worked example that explains the associated procedures (Reisslein et al., 2006).

The worked example-problem solving and problem solving-worked example sequences were compared in several studies (Hsu et al., 2015; Leppink, Paas, Van Gog, Vleuten \& Merrienboer, 2014; Van Gog et al., 2011). All these studies demonstrated the advantages of the 
worked example-problem solving sequences. For example, Van Gog et al. (2011) compared four example-based learning strategies - worked examples only, worked example-problem solving, problem solving-worked example, and problem solving only. The participants were secondary school students who were novices in the electrical circuits troubleshooting tasks. Results indicated no differences between worked examples only and worked example-problem solving or between problem solving-worked example and problem solving only, but the worked examples only and worked example-problem solving were more effective than problem solving only. Similarly, Leppink et al. (2014) showed that the example-example/example-problem condition was superior to the problem-example/problem-problem condition.

Role of expertise. According to the expertise reversal effect, the worked example effect is influenced by the level of learner expertise. With increased levels of learner knowledge in the task domain, the initial advantage of worked examples disappears, and with sufficiently high levels of learner expertise, problem solving may become even more effective than studying worked examples (Kalyuga, 2007). For example, Reisslein et al. (2006) investigated how learner expertise affected the effectiveness of different instructional sequences (worked exampleproblem solving vs. problem solving-worked example). The results supported an expertise reversal effect: novices benefitted more from the worked example-problem solving sequence, compared to more knowledgeable learners who benefitted more from the problem solvingworked example sequence.

\section{Present study}

The experiments reported in this paper conceptually replicated the studies of Van Gog et al. (2011) and Reisslein et al. (2006) on comparing the alternative example-based instructional sequences: worked example-problem solving vs. problem solving-worked example. However, 
the current study added a new experimental factor, element interactivity, into consideration. None of the previously conducted studies compared the two sequences from this perspective, with levels of element interactivity experimentally manipulated in a strictly controlled manner.

As mentioned above, levels of element interactivity are closely related to levels of learner expertise, therefore, it could be assumed that the worked example-problem solving sequence would be superior to the problem solving-worked example sequence for materials high in element interactivity (when novice learners are recruited) (Hypothesis 1), but this advantage would disappear or reverse for materials low in element interactivity (when expert learners are recruited) (Hypothesis 2).

\section{Experiment 1}

\section{Participants}

Fifty-two Year 5 students, around 10 to 11 years old, from one primary school in Indonesia participated in this experiment. In the $1^{\text {st }}$ phase of this study (low element interactivity tasks), 28 students were randomly assigned to the worked example-problem solving sequence, the rest 24 students were assigned to the problem solving-worked example sequence (See Figure 1). In the $2^{\text {nd }}$ phase of this study (high element interactivity tasks), half of the students in the Phase 1 worked example-problem solving sequence and half of the students in the problem solvingworked example sequence were randomly assigned to a new worked example-problem solving sequence in Phase 2, while the rest of students were assigned to a new problem solving-worked example sequence in Phase 2 (See Figure 2). Four students from the problem solving-worked example group in Phase 2 were excluded from the analysis, as they did not complete the whole procedure. All students were novices in geometry tasks used in this study. 
Worked Example-Problem Solving and Problem Solving-Worked Example

[Insert Figure 1 about here]

[Insert Figure 2 about here]

\section{Materials}

Learning materials. There were two sets of materials designed for each phase of this study separately. For the first phase, materials were 11 geometry formulas for calculating area of simple geometric shapes, such as the Area of a Circle. In the worked example-problem solving group, the students studied the list of formulas without pen/pencil, and then they generated the formulas in writing, whereas in the problem solving-worked example group, students generated the formulas in writing first, followed by studying the same list of formulas without pen/pencil. In Phase 2, the materials included tasks about calculating the area of composite shapes by applying formulas studied in Phase 1. Two pairs of worked example-problem solving and problem solving-worked example tasks were designed. For each pair of worked exampleproblem solving tasks, an example showing the full procedure for calculating the area of a composite shape (see Figure 3 for an example) was followed by a similar problem to solve; for each pair of problem solving-worked example tasks, the only difference was the order of presenting the worked example and the similar problem.

Assessing levels of element interactivity. We assumed that the materials used in Phase 1 were low in element interactivity. For example, when studying and memorizing the formula Area of a Circle $=\pi \times \mathrm{r} \times \mathrm{r}$, students needed to know the meanings of $\pi$ and $\mathrm{r}$, and the multiplication relationship between them, indicating a relatively low number of interactive elements (around four). Whereas, it was assumed that the materials in Phase 2 were high in element interactivity. For example, for novice learners facing the task showed in Figure 3, the 
first four elements were associated with identifying the four equal length lines, including the missing line FC, that form a rhombus. Then another four elements included identifying the four lines that constituted a trapezium, again including the missing line FC. To actually calculate the two areas, the students needed to know the meanings of $a$ and $b$ in the rhombus and the multiplication relationship between them, as well as the meanings of $a, b$, and $h$ in the trapezium and addition, multiplication, and division by 2 , that together added nine elements. Finally, adding together those two separate area values involved another element. Therefore, in total, around 18 interactive elements were involved in this task, making it high in element interactivity, compared to the formulas in Phase 1.

[Insert Figure 3 about here]

Post-content tests. A cued-recall test (for materials low in element interactivity) was designed and administered at the end of Phase 1 . The order of the 11 geometry formulas in the cued-recall test was randomized, based on the order used in the learning phase. A post-content test (for materials high in element interactivity) with five questions on calculating the area of composite shapes (similar to the problems in Phase 2 learning) was designed and administered at the end of Phase 2.

\section{Procedure}

This joint study was approved by the University ethics committee of the Institute of Research and Community Service. The approval numbers are 378/UN34.21/TU/2018 for Experiment 1 and 817/UN34.21/TU/2018 for Experiment 2.

In Phase 1, students were randomly allocated to the alternative experimental sequences (worked example-problem solving or problem solving-worked example) (See Figure 1), and sat 
in different rooms (10 minutes for moving class). All students studied 11 formulas first (10 minutes). Then the students in the worked example-problem solving group were presented the same 11 formulas again (10 minutes), followed by generating these formulas (10 minutes), whereas students in the problem solving-worked example group were required to generate the 11 formulas first (10 minutes), followed by the presentation of these formulas (10 minutes). A cuedrecall test of the 11 formulas was conducted at the end of this phase ( 8 minutes), the Cronbach $\alpha$ $=.80$.

In Phase 2, all participants had been firstly randomly re-allocated to new experimental groups, as described in the Participants section (See Figure 2). All the students were again presented with the same 11 formulas as in Phase 1 as a review, and the researcher provided an introduction to the compound shapes as combinations of common shapes. The students were shown two examples of compound shapes (10 minutes). After that, students in different groups sat in different rooms (10 minutes for moving class). The students in the worked exampleproblem solving group were presented the first pair of worked example-problem solving tasks, followed by the second pair, whereas the students in the problem solving-worked example group were presented the first pair of problem solving-worked example tasks, followed by the second pair (20 minutes). The only difference between the two groups was the order of presenting the worked example and the problem. Finally, a post-content test, including questions that were similar to those used during the Phase 2 learning, on calculating the area of compound shapes was conducted (10 minutes), the Cronbach $\alpha=.84$.

\section{Scoring}

When scoring the cued-recall test, 1 mark was given to each correctly recalled formula, therefore, the total of 11 marks could be awarded for the cued-recall test. For the second phase 
test, three marks were given to each question: 1 mark for correctly calculating the area of one separated shape; 1 mark for correctly calculating the area of another separated shape; and 1 mark for adding the two separate areas together. Therefore, the total of 15 marks for five questions could be awarded for the test. The carry-over errors were considered when marking the test. For example, if the area of the first shape was calculated incorrectly ( 0 mark $)$, but the area of the second shape was correct ( 1 mark) and the addition of the two values was performed correctly (1 mark), even if the final answer was incorrect, two marks were allocated for the task.

\section{Results}

A 2 (sequences: worked example-problem solving vs. problem solving-worked example) $\times 2$ (levels of element interactivity: low vs. high) repeated measures ANOVA was conducted with the second factor repeatedly measured. The raw test scores for both post-tests were converted to the percentage correct scores (Table 1).

[Insert Table 1 about here]

The main effect of sequence was not significant, $F(1,46)=.005, \operatorname{MSE}=729.56, p=.944$, $\eta_{p}^{2}=0$. The main effect of element interactivity was also not significant, $F(1,46)=.144$, MSE $=$ 488.72, $p=.706, \eta_{p}^{2}=.003$. However, the interaction between sequence and element interactivity was significant, $F(1,46)=8.291, \mathrm{MSE}=488.72, p=.006, \eta_{p}^{2}=.153$. Following the significant interaction, simple effect analyses were conducted. For materials that were low in element interactivity (the cued-recall test), there was no significant difference between the sequences, $\mathrm{t}(47)=-1.45, \mathrm{SE}_{\text {diff }}=7.486, p=.154, d=.41$, whereas, for materials that were high in element interactivity (the post-content test), the effect of sequence was significant, $\mathrm{t}(47)=2.15, \mathrm{SE}_{\mathrm{diff}}=$ 
$6.913, p=.037, d=.59$, indicating that the worked example-problem solving sequence was superior to the problem solving-worked example sequence.

Experiment 1 demonstrated the superiority of the worked example-problem solving sequence with novice learners, but only for materials high in element interactivity (area of composite shapes). For materials low in element interactivity (formulas for simple common geometric shapes), the superiority of the problem solving-worked example sequence was not found (although the effect size of 0.41 indicated a possibility of the effect). Thus, for novice learners, the superiority of the worked example-problem solving sequence for materials high in element interactivity disappeared with materials low in element interactivity.

Since the level of element interactivity depended on levels of learner expertise, materials high in element interactivity for novices could become low in element interactivity for relatively more experienced learners. Therefore, in Experiment 2, more knowledgeable learners were used, with the same sets of materials, to further compare the effectiveness of worked example-problem solving and problem solving-worked example sequences.

\section{Experiment 2}

\section{Participants}

Ninety-six Year 8 students, around 13 to 14 years old, from one secondary school in Indonesia participated in this experiment. In the first phase of this study, 48 students were randomly assigned to the worked example-problem solving sequence, the rest 48 students were assigned to the problem solving-worked example sequence (Figure 1). In the second phase of this study, exactly the same procedure as in Experiment 1 was used for randomly re-allocating participants to new experimental groups (Figure 2). Four students from the problem solving- 
worked example group in Phase 2 were excluded from the analysis, as they did not complete the whole procedure. All students had been previously taught the type of geometry tasks that were used in this study and therefore were considered to be relatively knowledgeable in the task domain.

\section{Materials}

All materials were identical to those used in Experiment 1. However, as students in this experiment had been previously instructed on how to calculate the area of composite shapes, they could retrieve the relevant schemas as single entities. Therefore, the materials used in both phases of this experiment were low in element interactivity for the participants.

\section{Procedure and Scoring}

The procedure and scoring were the same as in Experiment 1.

\section{Results}

A 2 (sequences: worked example-problem solving vs. problem solving-worked example) x 2 (levels of element interactivity: low vs. high) repeated measures ANOVA was conducted with the second factor repeatedly measured. The raw post-tests scores were converted to the percentage correct scores (Table 2).

[Insert Table 2 about here]

The effect of sequence was not significant, $F(1,90)=.233, \mathrm{MSE}=351.11, p=.631, \eta_{p}^{2}$ $=.003$. The effect of element interactivity was not significant, $F(1,90)=1.814, \mathrm{MSE}=368.80, p$ $=.181, \eta_{p}^{2}=.020$. The interaction between sequence and element interactivity was also not significant, $F(1,90)=2.152, \mathrm{MSE}=368.80, p=.146, \eta_{p}^{2}=.023$. Therefore, the results 
confirmed that for materials low in element interactivity (geometric formulas and area of composite shapes) in both phases of Experiment 2, there were no significant differences between the worked example-problem solving and problem solving-worked example sequences. The superiority of the worked example-problem solving sequence for high element interactivity tasks found in Experiment 1 with novices disappeared in Experiment 2 with more knowledgeable learners, which might indicate an expertise reversal effect.

\section{General Discussion}

This randomized, controlled experimental study was designed to investigate relations between the effectiveness of worked example-problem solving and problem solving-worked example sequences by experimentally manipulating the levels of element interactivity of the corresponding materials.

In Experiment 1, novices in the task domain learned how to calculate the area of compound shapes after learning some relevant geometric formulas. The results showed the advantage of using the worked example-problem solving sequence for learning materials high in element interactivity, confirming Hypothesis 1, whereas there were no differences between the worked example-problem solving and problem solving-worked example sequences for learning materials low in element interactivity, confirming Hypothesis 2.

In Experiment 2, more knowledgeable learners were recruited to learn the same sets of materials. Since they had been previously taught how to solve the type of tasks used in the experiment, all sets of materials were low in element interactivity for these participants. Accordingly, the results showed no differences between the worked example-problem solving and problem solving-worked example sequences for all sets of materials, confirming again 
Hypothesis 2. The superiority of the worked example-problem solving sequence found in Experiment 1 (with novice learners) disappeared in Experiment 2 (with more experienced learners), demonstrating an expertise reversal effect.

In summary, the study demonstrated that worked examples presented prior to problem solving were more effective than the reversed sequence for high element interactivity materials, with no difference between the sequences for low element interactivity materials. This study replicated the results of Van Gog et al. (2011) and Reisslein et al. (2006) indicating the superiority of worked example-problem solving sequences for novices' learning, but the study also extended their results by considering levels of element interactivity of instructional materials. Namely, the results of Van Gog et al. (2011) and Reisslein et al. (2006) might be also explained from the point of view of element interactivity. The superiority of the worked example-problem solving sequence was found with novices, because for materials high in element interactivity, using worked examples first reduced the learners' working memory load, which was in line with the worked example effect in cognitive load theory (Chen et al., 2015, 2016a, 2016b). The superiority of the worked example-problem solving sequence disappeared or reversed, because the materials were low in element interactivity for more knowledgeable learners, making worked examples redundant for the learners (and unnecessarily increasing their working memory load due to processing redundant information).

The results are also in accord with the previous research in cognitive load theory that demonstrated that for novice learners, the example-problem instructional sequence outperformed the problem-example sequence (Hsu et al., 2015; Leppink et al., 2014; Van Gog et al., 2011), as well as with studies by Glogger-Frey, Fleischer, Grüny, Kappich, \& Renkl, (2015) and GloggerFrey, Gaus, \& Renkl (2017). Glogger-Frey et al. (2015) found an advantage for guidance over 
invention activities, whereas, the opposite result was obtained by Glogger-Frey et al. (2017). The changed result was caused by the increased learning time for the 2017 study, compared to the 2015 study, which was the major difference between the two papers (Sweller \& Paas, 2017). Increases in learning time resulted in increases in expertise with the attendant decreases in element interactivity. With low element interactivity, guidance was redundant and generation activities became more important which is exactly the point being made in the current paper.

This study did not obtain any strong evidence in support of the problem solving-worked example sequence, as there were no significant differences for low element interactivity materials (even though a medium-size effect in Experiment 1 showed a trend). Still, the concept of element interactivity in cognitive load theory may indicate the conditions under which this approach becomes preferable to the worked example-problem solving instructional sequence. In relation to this, one major limitation of this study was that the materials were mostly associated with learning procedural knowledge. There is a strong indication though, originating from research in productive failure and invention learning approaches (Loibl \& Rummel, 2014a, 2014b; DeCaro \& Rittle-Johnson, 2012; Kapur, 2014), that problem solving-worked example sequences could be beneficial for learning conceptual knowledge by novice learners. It is possible to speculate that in case of conceptual knowledge, the initial problem-solving attempts, even if unsuccessful, could familiarize learners with some essential elements of the task, at least in isolated rather than interactive form and without much meaning assigned at this stage. Such initial rudimentary learning could allow reducing working memory load during the following comprehensive explicit instruction phase. In cognitive load theory, this method has been associated with the so-called isolated-interactive elements effect (Sweller et al., 2011). Future empirical studies within a cognitive load framework may need to take a closer look at this matter 
when investigating the effectiveness of alternative sequences of explicit instruction and problem solving for learning conceptual knowledge.

Other limitations of this study are the absence of delayed post-tests and differential retention and transfer tasks in the post-tests. Judging by the results of studies within productive failure and invention learning frameworks, problem-first sequences might be most effective when evaluated by delayed transfer tests. Such tests need to be included in future studies, together with thorough analyses and comparisons of levels of element interactivity of learning tasks.

In summary, the major theoretical implication of this study is that by considering the factor of element interactivity, the results of the two reported experiments provide a potential way of explaining the contradictory findings within different theoretical frameworks in relation to the effectiveness of alternative sequences of worked examples and problem solving tasks. For learning materials high in element interactivity, the worked example-problem solving sequence is likely to be more effective, whereas, for materials low in element interactivity, the problem solving - worked example sequence could be superior.

\section{Educational Implications}

The results of this study may inform educational practitioners that novice learners dealing with complex information that is difficult to process in limited-capacity working memory should initially be presented with sufficient instructional guidance, such as that provided by worked examples. With increases in learner levels of expertise, a gradual shift to a heavier emphasis on problem solving may be beneficial. Also, the teachers need to carefully consider both the nature 
Worked Example-Problem Solving and Problem Solving-Worked Example

of learning materials and levels of learner prior knowledge when using worked example-problem solving and problem solving-worked example instructional sequences. 
Worked Example-Problem Solving and Problem Solving-Worked Example

\section{References}

Chen, O., Kalyuga, S., \& Sweller, J. (2015). The worked example effect, the generation effect, and element interactivity. Journal of Educational Psychology, 107, 689-704. DOI: $10.1037 / \mathrm{edu} 0000018$

Chen, O., Kalyuga, S., \& Sweller, J. (2016a). Relations between the worked example and generation effects on immediate and delayed tests. Learning and Instruction, 45, 20-30. DOI: 10.1016/j.learninstruc.2016.06.007

Chen, O., Kalyuga, S., \& Sweller, J. (2016b). When instructional guidance is needed. The Educational and Developmental Psychologist, 33, 149-162. DOI: 10.1017/edp.2016.16

Chen, O., Kalyuga, S., \& Sweller, J. (2017). The expertise reversal effect is a variant of the more general element interactivity effect. Educational Psychology Review, 29, 393-405. DOI: $10.1007 / \mathrm{s} 10648-016-9359-1$

Chen, O., Retnowati, E., \& Kalyuga, S. (2019). Effects of worked examples on step performance in solving complex problems. Educational Psychology, 39, 188-202. DOI: $10.1080 / 01443410.2018 .1515891$

Cowan, N. (2001). Metatheory of storage capacity limits. Behavioral and Brain Sciences, 24, 154-176.

Cooper, G., \& Sweller, J. (1987). Effects of schema acquisition and rule automation on mathematical problem-solving transfer. Journal of Educational Psychology, 79, 347-362. DOI: $10.1037 / 0022-0663.79 .4 .347$

DeCaro, M. S., \& Rittle-Johnson, B. (2012). Exploring mathematics problems prepares children to learn from instruction. Journal of Experimental Child Psychology, 113, 552-568. DOI: 10.1016/j.jecp.2012.06.009 
Worked Example-Problem Solving and Problem Solving-Worked Example

Ericsson, K. A., \& Kintsch, W. (1995). Long-term working memory. Psychological Review, 102, 211-245. DOI: 10.1037/0033-295X.102.2.211

Glogger-Frey, I., Fleischer, C., Grüny, L., Kappich, J., \& Renk1, A. (2015). Inventing a solution and studying a worked solution prepare differently for learning from direct instruction. Learning and Instruction, 39, 72-87. DOI: 10.1016/j.learninstruc.2015.05.001

Glogger-Frey, I., Gaus, K., \& Renkl, A. (2017). Learning from direct instruction: Best prepared by several self-regulated or guided invention activities? Learning and Instruction, 51, 2635. DOI: 10.1016/j.learninstruc.2016.11.002

Hsu, C.-Y., Kalyuga, S., \& Sweller, J. (2015). When should guidance be presented in physics instruction? Archives of Scientific Psychology, 3, 37-53. DOI: 10.1037/arc0000012

Kalyuga, S. (2007). Expertise reversal effect and its implications for learner-tailored instruction. Educational Psychology Review, 19, 509-539. DOI: 10.1007/s10648-007-9054-3

Kapur, M. (2014). Productive failure in learning math. Cognitive Science, 38, 1008-1022. DOI: $10.1111 / \operatorname{cogs} .12107$

Kirschner, P. A., Sweller, J., \& Clark, R. E. (2006). Why minimal guidance during instruction does not work: An analysis of the failure of constructivist, discovery, problem-based, experiential, and inquiry-based teaching. Educational psychologist, 41, 75-86. DOI: $10.1207 / \mathrm{s} 15326985 \mathrm{ep} 4102 \_1$

Leppink, J., Paas, F., Van Gog, T., van Der Vleuten, C. P., \& Van Merrienboer, J. J. (2014). Effects of pairs of problems and examples on task performance and different types of cognitive load. Learning and Instruction, 30, 32-42. DOI:

10.1016/j.learninstruc.2013.12.001 
Worked Example-Problem Solving and Problem Solving-Worked Example

Loibl, K., \& Rummel, N. (2014a). The impact of guidance during problem-solving prior to instruction on students' inventions and learning outcomes. Instructional Science, 42, 305-326. DOI: 10.1007/s11251-013-9282-5

Loibl, K., \& Rummel, N. (2014b). Knowing what you don't know makes failure productive. Learning and Instruction, 34, 74-85. DOI: 10.1016/j.learninstruc.2014.08.004

Miller, G. A. (1956). The magical number seven, plus or minus two: Some limits on our capacity for processing information. Psychological Review, 63, 81-97. DOI: 10.1037/h0043158

Paas, F. (1992). Training strategies for attaining transfer of problem-solving skill in statistics: A cognitive-load approach. Journal of Educational Psychology, 84, 429-434. DOI: $10.1037 / 0022-0663.84 .4 .429$

Paas, F., \& Van Merriënboer, J. J. (1994). Variability of worked examples and transfer of geometrical problem-solving skills: A cognitive load approach. Journal of Educational Psychology, 86, 122-133. DOI: 10.1037/0022-0663.86.1.122

Peterson, L., \& Peterson, M. J. (1959). Short-term retention of individual verbal items. Journal of Experimental Psychology, 58, 193-198. DOI: 10.1037/h0049234

Reisslein, J., Atkinson, R. K., Seeling, P., \& Reisslein, M. (2006). Encountering the expertise reversal effect with a computer-based environment on electrical circuit analysis. Learning and Instruction, 16, 92-103. DOI: 10.1016/j.learninstruc.2006.02.008

Schwonke, R., Renkl, A., Krieg, C., Wittwer, J., Aleven, V., \& Salden, R. (2009). The workedexample effect: Not an artefact of lousy control conditions. Computers in Human Behavior, 25, 258-266. DOI: 10.1016/j.chb.2008.12.011

Sweller, J., Ayres, P., \& Kalyuga, S. (2011). Cognitive load theory. New York: Springer. 
Worked Example-Problem Solving and Problem Solving-Worked Example

Sweller, J., \& Chandler, P. (1994). Why some material is difficult to learn. Cognition and Instruction, 12, 185-233. DOI: 10.1027/s1532690xci1203_1

Sweller, J., \& Cooper, G. (1985). The use of worked examples as a substitute for problem solving in learning algebra. Cognition and Instruction, 2, 59-89.

Sweller, J., \& Paas, F. (2017). Should self-regulated learning be integrated with cognitive load theory? A commentary. Learning and Instruction, 51, 85-89. DOI: 10.1016/j.learninstruc.2017.05.005

Sweller, J., \& Sweller, S. (2006). Natural information processing systems. Evolutionary Psychology, 4, 434-458. DOI: 10.1177/147470490600400135

Tindall-Ford, S., Chandler, P., \& Sweller, J. (1997). When two sensory modes are better than one. Journal of Experimental Psychology: Applied, 3, 257-287. DOI: 10.1037/1076898X.3.4.257

Van Gog, T., Kester, L., \& Paas, F. (2011). Effects of worked examples, example-problem, and problem-example pairs on novices' learning. Contemporary Educational Psychology, 36, 212-218. DOI: 10.1016/j.cedpsych.2010.10.004 